\title{
Sciendo
}

\section{FEEDING COMPLETE CONCENTRATE PELLETS CONTAINING GROUND GRAINS OR BLEND OF STEAM-FLAKED GRAINS AND OTHER CONCENTRATE INGREDIENTS IN RUMINANT NUTRITION - A REVIEW}

\author{
Seyed Hadi Ebrahimi \\ Department of Animal Science, Faculty of Agriculture, Ferdowsi University of Mashhad, \\ PO Box 91775-1163, Mashhad, Iran \\ Corresponding author: shebrahimi@um.ac.ir
}

\begin{abstract}
The feed industry has attempted to encourage the animal husbandry sector to feed complete concentrate pellets containing ground grains in ruminant nutrition and thus prevent farmers from making concentrate in their farms. Reducing particle size using pre-pelleting grinding and pressing materials during pellet formation, plus starch gelatinization by heat treatment in the conditioner are key factors determining the extent and rate of starch digestion in ingested pellets. If prepelleting grinding of corn and barley grain for using in the pelleted concentrate results in ground materials of less than $1.8 \mathrm{~mm}$ mean particle size (especially in the case of barley grain which is highly fermentable), then it increases the rate of fermentability in the rumen which in turn increases the acidosis risk. Such situation and dissatisfaction from pellets feeding to ruminant have directed farmers to produce homemade mash concentrate which may include steam-flaked form of grains in the concentrate mixture. Pelleting process increases the time needed to collapse the pellet in the rumen so delays the access of microbes to fermentable organic matter. This counterbalance property highly depends on pellet size with highest effect obtained using $10 \mathbf{~ m m}$ diameter pellets for cattle. Feeding separately steam-flaked grains (plus other pelleted/mash non-grain ingredients of concentrate) may give results similar to the complete concentrate pellets having ground grains prepared according to optimized recommendations (pellet diameter and grain mean particle size). Nonetheless cost benefit studies are necessary to adopt one of the above two optimized technologies that has higher starch utilization and lower fecal starch excretion by animal. In the situation where consuming steam-flaked grains has priority of application in the diet, it is strongly recommended to pellet non-grain portions of concentrate for obtaining numerous pellet advantages such as reducing transportation cost, dust, sorting and bird removal.
\end{abstract}

Key words: ruminant, grain processing, steam-flaking, pelleting, particle size

Grains are a major source of starch and energy in high-yielding dairy and beef animals. These animals and other domestic ruminants consume at least $13.3 \%$ of the 
world's cereal grains (Bruinsma, 2003). Whole grains, ground in mash or pelleted concentrate and steam-flaked are the most commonly used form of grains for ruminant feeding. Commercial concentrate mixtures prepared in compound feed plants were introduced to the livestock sector to enable farmers to use higher technology levels, which may not be available to individuals in the farm. Readymade concentrate mixture will also help farmers focus more on herd management issues instead of spending time on purchasing raw materials, mineral supplements and other components. Finished products in a feed mill are mainly in form of pellets which would be steam treated in the conditioner machine. Advantages of feeding complete concentrate pellets are: increasing feed intake, reducing feed wastage, spending less time and energy on eating, preventing the sorting of feed ingredients by animals, and increasing bulk density (Abdollahi et al., 2013). Carlson et al. (2018) studied the nutrients of lactating dairy cows total mix ration (TMR) which contained pelleted or mash concentrate but was damaged by birds. They found that when both treatments were exposed to starling, the starch content in the TMR containing mash concentrate and in those having pelleted concentrate (10 mm diameter) were 24.55 and $28.69 \%$, respectively.

Despite the above advantages of pelleted concentrate containing ground grain, farmers do not show interest to use complete pelleted concentrate. Reason for such disinclination is that reducing grain particle size by pre-pelleting grinding (which is necessary for proper mixing and appropriate durability of the pellets) and further during pressing and pellet formation, in addition to starch gelatinization during pelleting process, increase uncontrolled ruminal fermentation which enhances risk of acidosis (Gimeno et al., 2015). Therefore, alternative methods were introduced to the feed industry for increasing digestibility without reducing particle size (Matsushima, 2006). For example, fecal starch concentrations were significantly lower in beef animals fed steam-flaked corn compared to those consuming dry-rolled corn, ground corn and whole corn treatments (Corona et al., 2005). The National Research Council (NRC, 2001) recommended that steam-flaked corn can be used to a higher extent compared to dry ground form in the glucogenic diets of lactating dairy cows presumably because of its lower acidosis potential.

Practically, using steam-flaked grains in the ration requires feeding a blend of processed grains and concentrate ingredients. If non-grain portions of the concentrate are in a mash form, they may pose a threat to the pelleting process, which challenges the conventional objectives of complete concentrate pelleting. The main question in this regard is whether a combination of grinding, conditioning and pelleting can be equal to the steam-flaking of a grain in terms of rumen degradability, health and small intestinal digestibility or not. Another question is what are the quality assurance factors that guarantee this equalization. Research articles are still being published on the necessity of adjustment factors for the energy value of the grains based on their mean particle size (Gallo et al., 2018). Optimum size of complete compound feeds pellet for reducing the risk of acidosis in ruminants is also under debate (Castrillo et al., 2013) and currently it has been found that within an acceptable range of flake density in the steam-flaked corn, enzyme accessibility significantly varied (Schwandt et al., 2016). The main 
objective of the present study was to explore technical circumstances that guarantee healthy employment of complete concentrate pellets containing ground grains in the diet of ruminant as safe as feeding a blend of concentrate having steam-flaked grains with particular references in ruminal health and degradability.

\section{Review and discussion}

Basis study references

Four groups of publications were searched and selected for preparing this review. The first group consisted of those that used dry ground grains (mainly corn and barley) in the concentrate mixture without steam treatment with focusing on their mean particle size. The second group of publications used pelleted concentrate in the diet of ruminants or discussed advantages of pelleting and technical points regarding factors influencing pellet quality with emphasis on ruminant benefits. Articles focusing on steam-flaked grain in the diet of ruminant and optimal use of this process were the third group and the fourth collection was comprised of publications that studied technologies comparatively for a better performance judgment.

\section{Pre-pelleting grains particle size; a key factor}

Since the 1840s, dry grinding of grains by hammer mill has been a common approach for reducing particle size and increasing surface for the action of enzymes and microbes (Matsushima, 2006). Ground forms of grains are also necessary for proper mixing with other ingredients and appropriate durability of the pellets; however, pressing the material at the time of pellet forming decreases particle size (Abdollahi et al., 2013). In this regard, Khan (2014) obtained 504, 820 and $985 \mu \mathrm{m}$ mean particle size when barley was pre-pelleting ground by 2, 4 and $6 \mathrm{~mm}$ screen, respectively. The mean particle sizes were further reduced to 247, 411 and $568 \mu \mathrm{m}$ (about half, measured with wet procedure) at post-pelleting process. A survey of fecal starch content in Midwestern U.S. feedlots fed with dry processed corn (hammer milled or rolled) showed an average of $190 \mathrm{~g} / \mathrm{kg}$ with a range of 70 to $366 \mathrm{~g} \mathrm{starch} / \mathrm{kg}$ feces (Schwandt et al., 2017). Therefore, depending on the type of the grain and animal species (sheep and goat or cattle) various recommendations can be applied for optimum pre-pelleting mean particle size of grains. For determining optimum mean particle size of corn and barley grains as components of pelleted concentrate, different aspects of grain particle size in a mash or pelleted concentrate mixture will be discussed in the following sections with particular reference to ruminant.

\section{Weight distribution of particle size or average particle size?}

Average particle size or geometric mean diameter $\left(\mathrm{d}_{\mathrm{gw}}\right)$ is calculated using the data obtained from the segregation of ground sample $(100 \mathrm{~g})$ by size. A vertical multiple dry or wet sieving is performed under gravity with mechanical agitation. AlRabadi (2013) analyzed starch content in barley particles which were subsequently fractionated on a set of eight sieves size of $0.045,0.125,0.250,0.5,1.0,1.7$ and $2.8 \mathrm{~mm}$ and found that particle size retained on the $1 \mathrm{~mm}$ sieve had the highest starch content, whereas the lowest starch content was observed for the particles retained 
by the $0.25 \mathrm{~mm}$ sieve. Fractionated materials retained above different sieve sizes (Figure 1) were examined for pancreatic $\alpha$-amylase and amyloglucosidase hydrolase rate in barley and sorghum grains. This was accomplished by in vitro digestion at $0,0.5,1,2,6$ and $24 \mathrm{~h}$, and there was a non-linear reduction in fractional-digestion rate coefficient $\left(\mathrm{h}^{-1}\right)$ of ground barley and sorghum by increasing size of the fractions (Al-Rabadi et al., 2009). In our laboratory, we compared two concentrate mixtures containing corn, barley, soybean meal, wheat bran, full fat soybean, meat meal, fish meal, corn gluten meal, mineral and vitamin supplement, commercial buffer mixture, sodium bicarbonate, dicalcium phosphate, vitamin $\mathrm{E}$ and $\mathrm{Se}$, toxin binder and Availa $^{\circledR} 4$ (an ingredient that contains a combination of organic zinc, manganese, copper and cobalt), at ratio of 310, 240, 200, 92.2, 40, 30, 25, 25, 15, 10, 7, 2, 2, 1 and $0.8 \mathrm{~g} / \mathrm{kg}$, respectively (Ebrahimi, unpublished data). One concentrate was produced in a commercial hammer feed mill having $6 \mathrm{~mm}$ sieve and the other one was prepared in the farm where grains were ground by a hammer mill with $3 \mathrm{~mm}$ sieve but there were no differences with regards to the formulation and ingredients. Figure 2 shows the particle size distribution and protein content of each of the fractions on the sieve in different finished products. The concentrate prepared in the feed mill contained greater proportion of coarse particles with lower crude protein $(\mathrm{CP})$ content $(\mathrm{b})$ compared to the farm-made concentrate (Figure $2 \mathrm{a}, 2 \mathrm{~b}$ ) which indicates that bigger particles were starchy constituents. Based on these findings, it can be concluded that for optimizing grinding process in the diet of ruminants, weight distribution of particle size, rather than average particle size should be used.

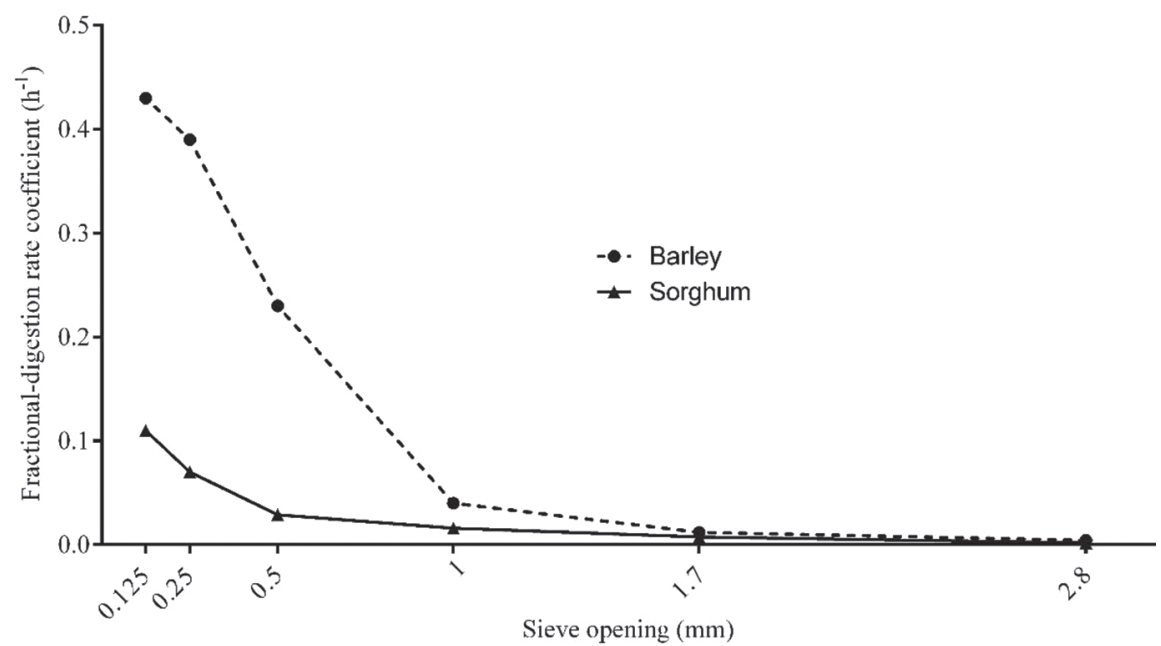

Figure 1. Fractional-digestion rate coefficient $\left(\mathrm{h}^{-1}\right)$ of ground barley and sorghum retained above different sieve size, after in vitro digestion at $0,0.5,1,2,6$ and $24 \mathrm{~h}$ with pancreatic $\alpha$-amylase and amyloglucosidase. Reproduced from Al-Rabadi et al. (2009) 
a

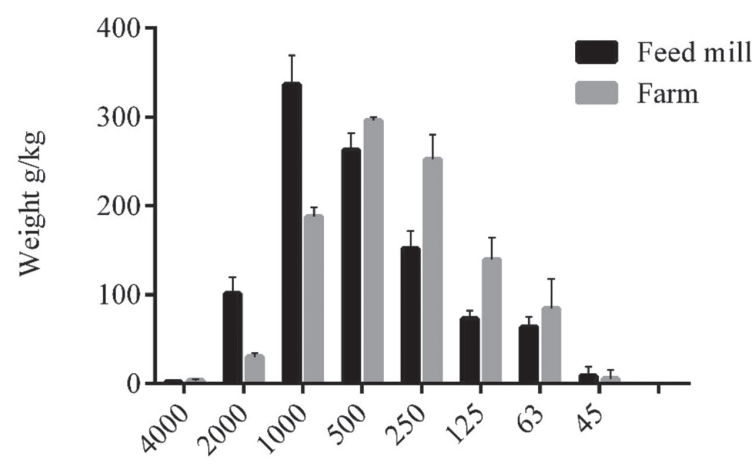

b

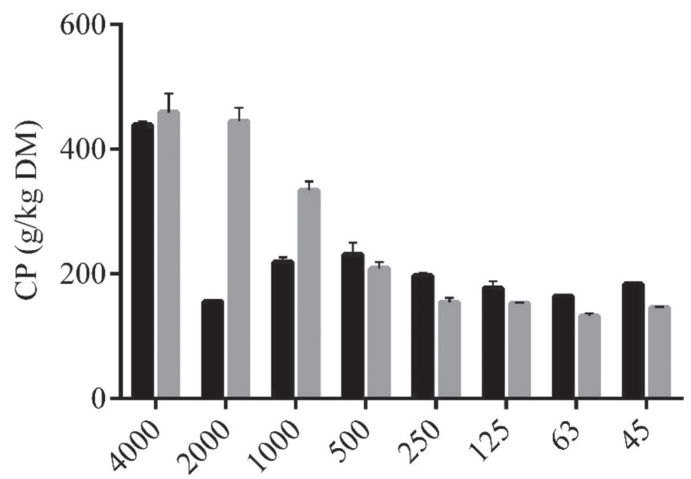

Diameter of sieve holes $(\mu \mathrm{m})$

Figure 2. Particle size distribution of concentrate mixtures similar in formula prepared in farm or in a feed meal differing in hammer meal screen size (a). Crude protein content of particles retained on the different sieves (b). Error bar indicates standard deviation

\section{Effect of grains particle size on pellet durability}

Factors such as the type of concentrate formula, particle size, conditioner circumstances, pellet feeding rate, die speed and design can influence pellet durability. Effect of particle size on pellet durability is summarized in Table 1. An earlier study (Stevens, 1987) showed that the grinding of corn grain into 1023, 794 and $551 \mu \mathrm{m}$ did not significantly affect pellet durability. Stark (1994) showed that reducing mean particle size in a corn/soybean meal-based concentrate could only slightly increase pellet durability from 97.3 to 98.5 . Fahrenholz (2012) also found that particle size has a small impact on pellet durability only at $65^{\circ} \mathrm{C}$ conditioner temperature, which vanished when the temperature increased to $85^{\circ} \mathrm{C}$. Durability of pellets with diameter of $4 \mathrm{~mm}$ containing whole wheat was $73.13 \%$ of same pellet size, made of ground wheat (Raaijmakers et al., 2017). When corn grain (in the poultry feed at the 
level of $588 \mathrm{~g} / \mathrm{kg}$ ) with $1857 \mu \mathrm{m}$ mean particle size was used in the pellets made using a die having $4.73 \mathrm{~mm}$ diameter holes (Reece et al., 1986), then pellet durability was $92.9 \%$. Considering such minor effects of particle size on pellet durability, feed plants can use bigger particle sizes for pellet components which increases production rate with lower energy consumption.

Table 1. Effects of mean particle size on pellet durability index

\begin{tabular}{cc|c|c|c|c|c}
\hline \multicolumn{4}{c|}{ References } \\
\hline \multicolumn{3}{c}{ Fahrenholz $(2012)^{\mathrm{a}}$} & \multicolumn{2}{c|}{ Stevens $(1987)$} & \multicolumn{2}{c}{ Stark (1994) } \\
\hline \multicolumn{2}{c|}{$\begin{array}{c}\text { Pellet } \\
\text { durability index }\end{array}$} & $\begin{array}{c}\text { Corn particle } \\
\text { size }(\mu \mathrm{m})\end{array}$ & $\begin{array}{c}\text { Pellet } \\
\text { durability } \\
\text { index }\end{array}$ & $\begin{array}{c}\text { Corn/Soy } \\
\text { particle size } \\
(\mu \mathrm{m})\end{array}$ & $\begin{array}{c}\text { Pellet } \\
\text { durability } \\
\text { index }\end{array}$ & $\begin{array}{c}\text { Corn particle } \\
\text { size }(\mu \mathrm{m})\end{array}$ \\
\hline 89.0 & 83.9 & 462 & 97.3 & 543 & 89.8 & 1023 \\
89.0 & 81.9 & 298 & 98.3 & 233 & 88.8 & 794 \\
& & & & & 90.3 & 551 \\
\hline
\end{tabular}

${ }^{a}$ Two different conditioner temperatures.

\section{Quantifying starch gelatinization in the pellet and steam-flaking processes}

In addition to reducing particle size, pelleting causes starch gelatinization and subsequently increases digestibility in the digestive tract. Table 2 illustrates the effects of pelleting and steam-flaking on gelatinized starch content. In maize-based broiler diets, pelleting increased the content of gelatinized starch from 5.9 to $16.9 \mathrm{~g} /$ $\mathrm{kg}$ starch at $75^{\circ} \mathrm{C}$ conditioner temperature (Abdollahi et al., 2010). Lewis (2014) pelleted corn $(405.5 \mathrm{~g} / \mathrm{kg})$ and soybean meal $(252.5 \mathrm{~g} / \mathrm{kg})$ based concentrate which had an average particle size of $592 \mu \mathrm{m}$ (after mixing) by conditioning at $77^{\circ} \mathrm{C}$ for $30 \mathrm{~s}$, and found that gelatinized starch increased from 17.59 to $25.0 \mathrm{~g} / \mathrm{kg}$ starch as a result of the pelleting process. Steam temperature and retention time are major conditioner factors which influence the degree of gelatinization and different conditioners have been invented for this purpose (Bedford and Partridge, 2010). Super-conditioners have flexibility for a wide range of temperatures and retention times depending on the type of grain. This technology could improve nutrients digestibility more than conventional conditioners (Attar et al., 2018).

The degree of starch gelatinization in the pelleted concentrate was found to be a function of particle size. Muramatsu et al. (2014) investigated starch gelatinization after the pelleting of corn-soybean meal broiler diet (Table 2). The different diet particle sizes in this study were obtained by changing the hammer tip speed (3600 rotations per minute for medium-size grinding and 1800 rotations per minute for coarse-size grinding). Prior to grinding, all the ingredients were passed through a sieve with a $5.0 \mathrm{~mm}$ diameter hole size, and the coarse ingredients which did not pass through this screen were ground in a hammer mill with $5.0 \mathrm{~mm}$ diameter hole sieves. Average particle size of final products were 1024 and $743 \mu \mathrm{m}$. As presented in Table 2, coarse diet $(1024 \mu \mathrm{m})$ which was steam-conditioned for 15 seconds at 80 to $82^{\circ} \mathrm{C}$ under a steam pressure of 1.5 to 2.0 bar, was gelatinized 7 units more than the 
medium-size particles $(743 \mu \mathrm{m})$. Lykos and Varga (1995) from an in situ study for comparison of particle size with heat treatment, concluded that heat treatment had a stronger influence on rumen degradability of corn sources dry matter when comparing ground corn $(686 \mu \mathrm{m}$, mean particle size $)$ with steam-flaked corn $(0.36 \mathrm{~kg} / \mathrm{L}$ and $2896 \mu \mathrm{m}$ density and mean particle size, respectively). This indicates that greater gelatinization does not require fine particles.

Table 2. Effects of pelleting and steam-flaking on gelatinized starch content ( $\mathrm{g}$ per $100 \mathrm{~g}$ total starch) of corn grain or corn based diet

\begin{tabular}{c|c|c|c|c}
\hline \multicolumn{5}{c}{ References } \\
\hline Qiao et al. $(2015)^{\mathrm{d}}$ & $\begin{array}{c}\text { Muramatsu et al. } \\
(2014)^{\mathrm{c}}\end{array}$ & $\begin{array}{c}\text { Lewis et al. } \\
(2014)^{\mathrm{b}}\end{array}$ & $\begin{array}{c}\text { Abdollahi et al. } \\
(2010)^{\mathrm{a}}\end{array}$ & Physical form \\
\hline- & Not reported & 17.59 & 5.9 & un-pelleted diet \\
- & 37.15 or 30.15 & 25.0 & 16.9 & pelleted diet \\
16.70 & - & - & - & whole corn grain \\
56.30 & - & - & - & steam flaked corn \\
\hline
\end{tabular}

${ }^{a}$ Corn grain and soybean meal were 617.5 and $278.6 \mathrm{~g} / \mathrm{kg}$ and average particle size was not reported. Conditioners temperature was $75^{\circ} \mathrm{C}$ for $30 \mathrm{~s}$.

${ }^{\mathrm{b}}$ Corn grain and soybean meal were 405.5 and $252.5 \mathrm{~g} / \mathrm{kg}$ and average particle size was $592 \mu \mathrm{m}$. Conditioners temperature was $77^{\circ} \mathrm{C}$ for $30 \mathrm{~s}$.

${ }^{\mathrm{c}}$ Corn grain and soybean meal were 672.4 and $23.50 \mathrm{~g} / \mathrm{kg}$ and average particle size was 1024 or $743 \mu \mathrm{m}$. Higher value indicates gelatinized starch in the diet with $1024 \mu \mathrm{m}$ average particle size. Conditioners temperature was $82^{\circ} \mathrm{C}$ for $15 \mathrm{~s}$.

${ }^{\mathrm{d}}$ The steam chests temperature was $105^{\circ} \mathrm{C}$ with a 55 min retention time.

Steam-flaking is a grain-specific process and it requires particular circumstances for each type of grain. Profits of steam-flaking are greater in corn and sorghum than in wheat and barley (Armbruster, 2006). Steam-flaking of grains increases surface area as well as starch accessibility and digestibility by interrupting the protein matrix surrounding the starch granules (Zinn et al., 2002). Compared to dry treatment, steam flaking of corn increased amyloglucosidase reactivity of starch (Zinn, 1990). It increased both starch and non-starch organic matter digestibility which resulted in improvement in the net energy value of corn (Zinn et al., 2002), barley, wheat, and oat in cattle (Plascencia et al., 2018). Qiao et al. (2015) observed that starch gelatinization improved from 16.70 in whole grain to $56.30 \mathrm{~g} / \mathrm{kg}$ starch in the steamflaked corn. Density of steam-flaked corn is a sign of effective flaking and a range of 0.32 to $0.39 \mathrm{~kg} / \mathrm{L}$ has been reported to be acceptable for dairy cows (Plascencia and Zinn, 1996). However, when different steam-flaked corn collected from 17 commercial feed yards in 7 U.S. states were studied with respect to enzymatic starch availability (Schwandt et al., 2016), a negative correlation was found between flake density and enzymatic starch availability within the above-mentioned acceptable range (Figure 3). Such a negative correlation was already reported between rumen starch digestion and flake density (Zinn et al., 2002). Although the above fact was confirmed by Gutierrez et al. (2018) as they showed that increasing the flake density of corn grain (within above range) did not have any significant effect on the daily weight 
gain and carcass characteristics of crossbred steers. Zinn et al. (2002) stated that "adequacy of steam-flaking can be reliably predicted by measuring the starch concentration of feces". Zinn (1990) evaluated the different steaming times used for the production of steam-flaked corn to feed steers and found no advantage for steaming times greater than $34 \mathrm{~min}$. The critical factors influencing flake quality measures (e.g. flake density, flake thickness and starch reactivity) are presented in Table 3 . An optimum combination of moisture, heat and pressure is necessary to accomplish the complete benefits of flaking.

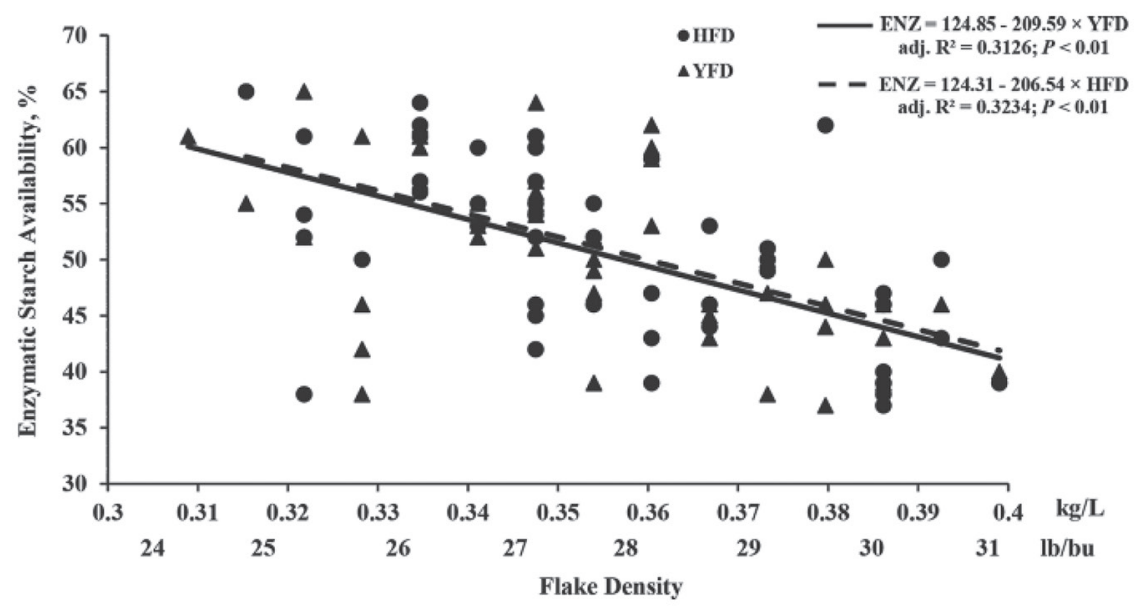

Figure 3. Negative correlation between enzymatic starch availability (ENZ) and flake density for 17 commercial feed yards surveyed in 7 US states. Flake density were measured either by yard personnel (YFD) or investigator (HFD). Adopted from Schwandt et al. (2016)

We have not found any documents comparing the degree of starch gelatinization in complete concentrate pellet having ground grains and concentrate mixture containing steam-flaked grains with the same origin. It is difficult to conclude effectiveness of steam cooking in pelleting and flaking process because in the steam-flaking, whole grain undergoes heat treatment whereas in the pellet making, ground materials pass through conditioner in a relatively very shorter time for receiving heat. Apparently, super-conditioned ground grains may undergo equal or even more starch gelatinization in comparison with steam-flaked ones. It should be added that conditioners provide similar operational conditions for all concentrate ingredients whereas in the steam-flaking, depending on the type of grains, there are different options (Table 3). 
Table 3. Critical factors influencing flake and pellet quality measures for ruminants

\begin{tabular}{ll}
\hline \multicolumn{1}{c}{ Factors } & \multicolumn{1}{c}{ Recommended range (Armbruster, 2006) } \\
\hline Moisture addition before steaming & $5-7 \%$ \\
Steeping time & $30 \mathrm{~min}$ to $12 \mathrm{~h}$ \\
Steam chests temperature & 95 to $105^{\circ} \mathrm{C}$ \\
& 20 to $30 \mathrm{~min}$ for wheat and barley \\
Retention time in steam chests & 30 to $40 \mathrm{~min}$ for corn \\
& 40 to $50 \mathrm{~min}$ for sorghum \\
Roll corrugation & 14 to 16 grooves per inch for corn \\
Roll gap & 0.8 to $1 \mathrm{~mm}$ for corn \\
\hline
\end{tabular}

\section{Effect of particle size and pelleting on digestibility}

Grain processing should aim: 1) to maximize whole tract digestibility, leading concentrations below $50 \mathrm{~g} / \mathrm{kg}$ of ingested starch into the feces, 2) to optimize starch degradation in the rumen with the highest VFA production without acidosis occurrence, and 3) to adjust intestinal digestion of starch with the lowest fermentation in the large intestine (Hutjens, 1999). However, whereas a large number of studies such as Coon et al. (2018) have focused on forage particle size, less attention has been paid to the potential effects of the physical form of the concentrate and pre- and post-pelleting grain particle size on animal performance. It has been reported that soybean meals particle size did not provoke animal and ruminal responses in the cattle (Netemeyer et al., 1980), which implies that grain particle size distribution has a major effect on the ruminal and post-ruminal digestibility of concentrate. A metaanalysis performed by Ferraretto et al. (2013) indicated that increasing dry ground or rolled corn mean particles from 500 to $1000 \mu \mathrm{m}$ to 3500 to $4000 \mu \mathrm{m}$ in the diet of lactating dairy cows resulted in the depression of starch digestibility from 0.993 to $0.777 \mathrm{~g} / \mathrm{kg}$. This significantly reduced total tract DM digestibility, but corn mean particle size was found to have no significant effect on milk production and fat content. Possibly, the effect of grain particle size on animal performance could not be explored by meta-analysis and is detectable only when the other ingredients, and in particular forage portions, are keept similar across all the treatments.

Ground corn with mean particle size of $0.83 \mathrm{~mm}$ and without steam treatment in the mash concentrate exhibited healthy rumen parameters in lactating dairy cows consuming $20 \mathrm{~kg} / \mathrm{d}$ dry matter and producing $36.1 \mathrm{~kg} / \mathrm{d}$ milk (Knowlton et al., 1996). Callison et al. (2001) tested dry ground corn at three mean particle sizes of 1.2, 2.6 and $4.8 \mathrm{~mm}$ in the absence of heat treatment in mash concentrate of lactating dairy cows. They concluded that mean particle size of $1.2 \mathrm{~mm}$ can be a desirable mean particle size for corn grain in the cattle ration. Rémond et al. (2004) used ground semiflint corn to three mean particle sizes of $0.7,1.8$ and $3.7 \mathrm{~mm}$ at the level of $36.4 \%$ in the diet of lactating dairy cows. They determined mean particle size of $0.7-1 \mathrm{~mm}$ as optimum size for this variety of maize when concentrate was used in mash form and there was no heat or steam treatment. They also reported that increasing mean particle size, linearly decreased total tract starch digestibility through 
depression in the ruminal starch degradability. Such condition resulted in a trend for lower milk production $(18.2 \mathrm{~kg} / \mathrm{d})$ in cows fed $15.5 \mathrm{~kg}$ DM of diet containing corn with $3.7 \mathrm{~mm}$ mean particle size in comparison to animals consuming $16 \mathrm{~kg}$ DM of diet having corn with $0.7 \mathrm{~mm}$ mean particle size which produced $19.8 \mathrm{~kg}$ milk daily. Interestingly, starch digestibility of small intestine and large intestine were not affected by corn mean particle size. Effective ruminal starch degradability was also estimated as $61.6,56.6$ and $49.5 \%$ in corn mean particle sizes of $0.7,1.8$ and $3.7 \mathrm{~mm}$ having passage rates of $4.99,5.16$ and $4.27 \% / \mathrm{h}^{-1}$. Kazemi-Bonchenari et al. (2017) used barley at the level of $350 \mathrm{~g} / \mathrm{kg}$ DM for male Holstein calves with two mean particle sizes of 1.2 and $2.4 \mathrm{~mm}$ in a mash concentrate without conditioning and they found no significant differences in animal performance and rumen parameters. Ghorbani et al. (2002) examined lactating diets containing $300 \mathrm{~g} / \mathrm{kg}$ DM barley with different mean particle size $(0.94,1.93$ and $2.90 \mathrm{~mm})$. There were no significant differences between fine and medium size of ground barley on milk yield and composition; but compared to fine grinding, greatest barley mean particle size $(2.90 \mathrm{~mm})$ showed lower milk production and dry matter digestibility in Holstein dairy cows. Gallo et al. (2016) focused on the effect of hammer-milled barley and corn mean particle size on the rate and extent of ruminal starch digestion. Within the studied range of 0.11 to $3.5 \mathrm{~mm}$, increasing the mean particle size of corn grain by $1 \mathrm{~mm}$ resulted in a linear decrease of starch degradation rate $\left(\operatorname{starch} \mathrm{k}_{\mathrm{d}=} 0.049 \mathrm{~h}^{-1}\right)$ and a $6.3 \%$ units decrease in ruminal starch degradability for $7 \mathrm{~h}$ incubation time. This effect was greater for barley, since a linear decrease of $0.092 \mathrm{~h}^{-1}$ and $6.5 \%$ was found in the starch $\mathrm{k}_{\mathrm{d}}$ and $7 \mathrm{~h}$ in vitro starch degradability (IVSD), respectively (Figure 4). As shown in Figure 4, when corn and barley were ground to $2 \mathrm{~mm}$ mean particle size (which is energetically profitable for producers), an IVSD of above $800 \mathrm{~g} / \mathrm{kg}$ was observed within $7 \mathrm{~h}$ rumen incubation for both grains (Gallo et al., 2016). Increasing mean particle size to 2.98 and $3.5 \mathrm{~mm}$ for barley and corn respectively, reduced IVSD below $800 \mathrm{~g} / \mathrm{kg}$ but effect of mean particle size was more pronounced on starch degradation rates. In another study (Gallo et al., 2018) on four starch sources, it was concluded that "mean particle size adjustment factors could be used to modify the starch-based feed energy values as a function of mean particle size". These findings indicate that energy value of grains is influenced by mean particle size.

Blasel et al. (2006) found that every $100 \mu \mathrm{m}$ increase in mean particle size of corn grain reduced $\alpha$-amylase starch accessibility by $2.7 \%$. In another study (Anguita et al., 2006), grinding through a sieve of $0.8 \mathrm{~mm}$ produced corn and barley with 499 and $382 \mu \mathrm{m}$ which had starch hydrolysis rate (during $240 \mathrm{~min}$ in vitro small intestinal incubation) of 0.69 and 0.82 for corn and barley, respectively. When sieve size increased to $3 \mathrm{~mm}$, mean particle size of 922 and 1535 with hydrolysis rates of 0.57 and 0.34 were found in corn and barley, respectively (Fig. 5). These results showed the reduction of $4.11 \%$ (corn) and $5.08 \%$ (barley) in rate of hydrolysis per $100 \mu \mathrm{m}$ increase in mean particle size. Figure 5 also illustrates that when barley and corn grains were ground through a sieve of $0.8 \mathrm{~mm}$, it resulted in finer particles for barley. Therefore, when aiming similar mean particles for these two grains, different grinding conditions must be adjusted or two separate hammer mills should be used. 

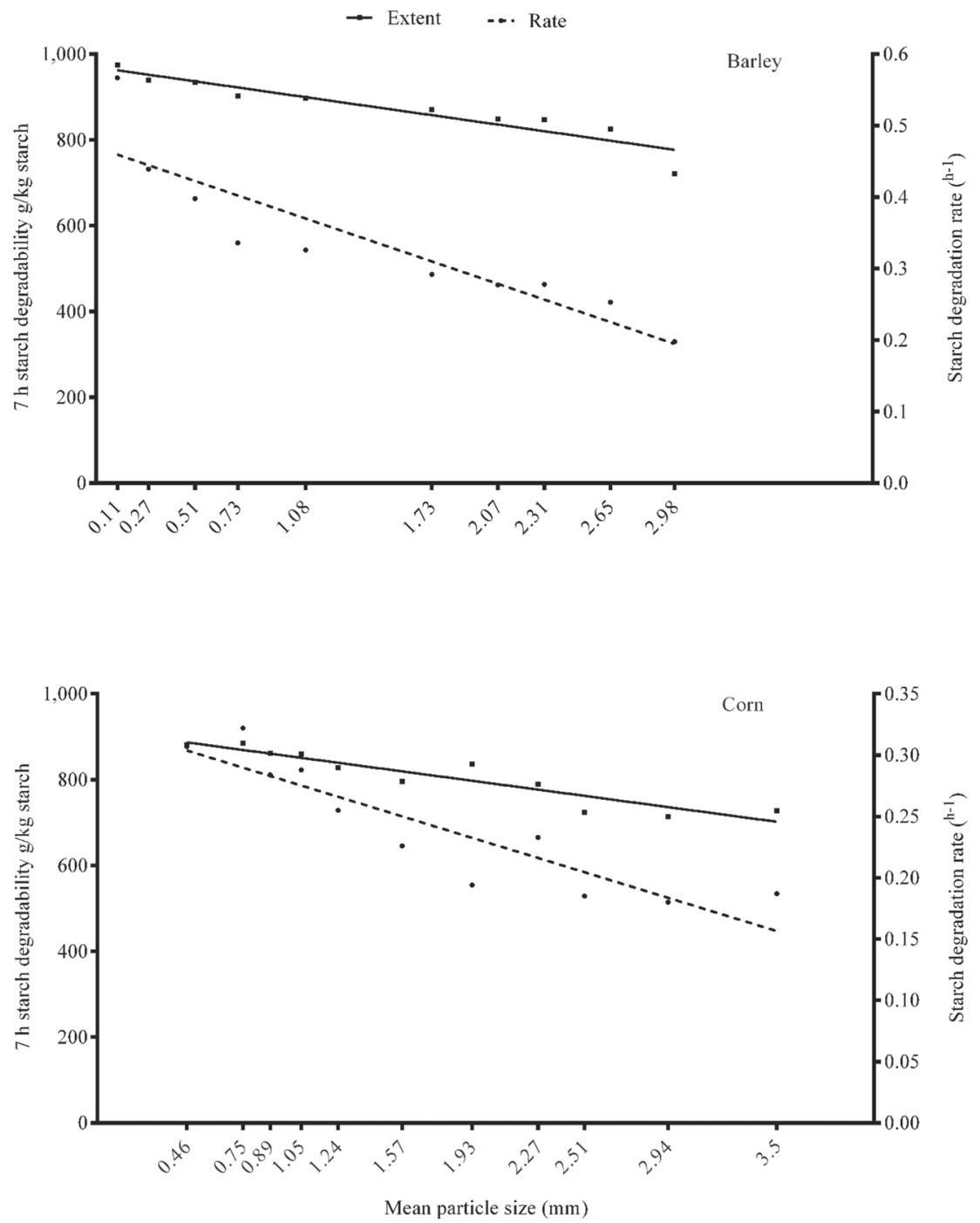

Figure 4. Extent and rate of $7 \mathrm{~h}$ in vitro starch degradation in the ground corn and barley with different mean particle size. Reproduced from Gallo et al. (2016)

Starch gelatinization has greater effects on ruminal starch digestion compared to particle size reduction. For instance, reducing mean particle size of dry ground corn through screen size of 3 to 1.5 and $0.75 \mathrm{~mm}$ resulted in $8 \mathrm{~h}$ ruminal starch disappearance of $11.5,12.5$ and $19 \%$, respectively. When steam-flaked $\left(100^{\circ} \mathrm{C}, 20 \mathrm{~min}\right)$ corn grains were similarly ground, starch disappearance increased from 30.7 to 36.9 and $40.8 \%$, in the screen size of 3 to 1.5 and $0.75 \mathrm{~mm}$, respectively (Galyean et al., 1981). 
Al-Rabadi et al. (2011) similarly performed an in vitro three steps enzymatic hydrolysis at $0,0.5,1.0,2.0,6.0$ and $24.0 \mathrm{~h}$ mimicking digestion in the mouth, stomach and small intestine on ground barley with average particle size of $0.684 \mathrm{~mm}$ without or with further heat treatment using extrusion. They found that potential starch digestibility changed from 0.876 to 0.920 . However, rate of starch digestion increased from 0.18 to $1.91 \mathrm{~h}^{-1}$ in the absence and presence of heat treatments, respectively.

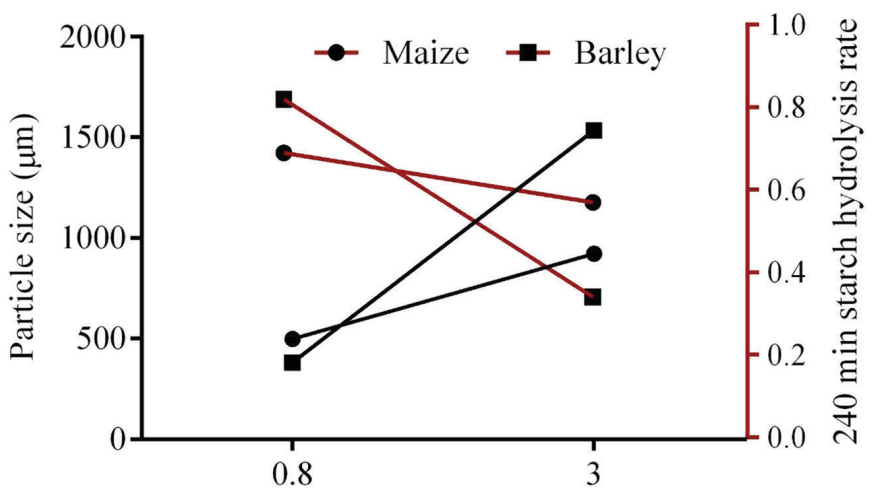

Mill sieve size $(\mathrm{mm})$

Figure 5. In vitro starch hydrolysis rate as affected by grain type and particle size. Reproduced from Anguita et al. (2006)

Shin-ichi et al. (2016) compared $72 \mathrm{~h}$ in situ rumen degradability of compound feeds in pellet $(6 \mathrm{~mm})$ and mash forms which were similar in composition. Pelleting increased soluble fraction by $16.47 \%$ and caused a decrease in potentially degradable fraction by $7 \%$. Similarly, when two types of concentrate (mash vs pellet) with similar formula were fed to Holstein bulls, pelleted concentrate at $6 \mathrm{~mm}$ caused a drop in the $4 \mathrm{~h}$ post feeding ruminal $\mathrm{pH}$ by $2.68 \%$ and therefore did not reduce the risk of subacute ruminal acidosis compared to the mash form (Gimeno et al., 2015). It should be noted that in this study, wheat straw was fed once a day as the sole source of forage, separately from the twice concentrate feeding. Presumably, feeding in TMR could lead to different results. Experiments on growing lamb fed with a ration containing $345 \mathrm{~g} / \mathrm{kg}$ bagasse pith as forage showed that pelleted concentrate increased intake, ADF and NDF apparent digestibility (Karimizadeh et al., 2017). Pelleting had no significant impact on average daily gain. However, eating, chewing, and ruminating times decreased in animals fed with pelleted form of concentrate compared to those fed with mash form. No information was presented regarding pellet diameter in this study.

Greater adhesion and density in the pellet particles may act as an inhibitory factor in fermentation, especially within the hour following its addition to the rumen (Bertipaglia et al., 2010). However pellet characteristics such as hardness and diameter directly influence the process. Bertipaglia et al. (2010) studied concentrate mixtures 
(containing 324, 100 and $50 \mathrm{~g} / \mathrm{kg}$ DM barley, corn and wheat, respectively) in mash form or pelleted with 3.5 and $10 \mathrm{~mm}$ diameter using in vitro technique without altering original particle size. They observed a decrease in gas production in the pelleted concentrates compared to the mash form within initial hours of incubation. When the above concentrates were fed to beef steers, post ruminal $\mathrm{pH}$ was 5.89 in cattle fed mash and 5.80 in those consuming $10 \mathrm{~mm}$ pelleted concentrate compared to 5.61 in those being fed smaller pellets (Castrillo et al., 2013). These findings indicate that pelleting may extend the time required to collapse the pellet and delays the access of microbes to fermentable organic matter. However, the counterbalance property of the pellet is highly size-dependent. Using small pellet sizes when forage and concentrate are separately fed to the animal may increase the risk of acidosis. This is why Matsushima (1979) mentioned that feeding pelleted concentrate to feedlot cattle consuming high levels of grain is not appropriate.

In the year 2000, grain processing index (PI) was introduced as a standard for particle size which was calculated using the following formula for steam rolled barley (Yang et al., 2000):

\section{$P I=$ (barley volume weight after processing / barley volume weight before processing) $\times 100$}

Based on this formula, lower PI indicates fine grinding and smaller particle size. Using in vitro, in situ and in vivo experiments, Yang et al. (2000) monitored the optimum value of $64 \%$ for maximum milk yield without acidosis signs. Although Koenig and Beauchemin (2011) and Moya et al. (2015) used this index to investigate its impact on feedlot steers fed steam rolled barley, no study has yet optimized PI for barley and other grains ground by hammer mills (which is being used both in the commercial feed plants and farms). Furthermore, from the viewpoint of rumen health, the lower limit of PI depends on the level of peNDF in the diet. Recently, it was found that type of the forage influenced total intake and rumen environment of cows which were gradually fed wheat grain (Russo et al., 2018). Therefore, the level of forage NDF and type of the forage should be taken into account for determining PI.

\section{Comparative studies}

Comparative studies in this regard have not evaluated the correct assessment for the relative superiority of feeding steam-flaked grains along with mash or pelleted other concentrate ingredients over other methods, including complete concentrate pellet having ground grains. For instance, steam-flaked grains have often been compared with fine or coarse dry ground forms in a mash concentrate which are not analogous, because the latter does not undergo heat treatment. When lactating Holstein cows were fed with a TMR diet containing $420 \mathrm{~g} / \mathrm{kg}$ steam-flaked sorghum grain $(0.36 \mathrm{~kg} / \mathrm{L})$, starch and OM digestibility were 24.37 and $9.70 \%$ greater than the groups fed with dry-rolled sorghum grain $(0.643 \mathrm{~kg} / \mathrm{L})$. This in turn led to an increase of $4.84 \%$ in the protein content of milk without affecting milk yield and feed conversion ratio (Oliveira et al., 1993). Different forms of corn grain have also been studied 
in the diet of crossbreed beef when animals were receiving $880 \mathrm{~g} / \mathrm{kg}$ concentrate mixture containing $753 \mathrm{~g} / \mathrm{kg}$ corn grain (Corona et al., 2005). Fecal starch concentrations were 1.75, 19.6, 16.15 and $25.91 \%$ however, body weight gain efficiency (average daily gain to dry matter intake) were $0.2,0.17,0.17$ and 0.16 for steam-flaked corn, dry-rolled corn, ground corn and whole corn treatments, respectively. In this study, no part of the concentrate mixtures was in the pellet form. Safaei et al. (2017) compared four concentrate mixtures which were similar in formulation but different in terms of the processing method of barley and corn in the diet of lactating dairy cows containing $400 \mathrm{~g} / \mathrm{kg}$ forage ( 0.25 corn silage and 0.15 alfalfa hay, DM basis). Treatments consisted of 1) un-pelleted concentrate with both grains ground by hammer mill (3 mm screen size), 2) blend of steam-flaked barley and corn, 3) blend of steam-flaked corn and ground barley, and 4) blend of steam-flaked barley and ground corn. In all the concentrates which had one or two steam-flaked grains (treatments 2, 3 and 4), non-steam flaked portions were in mash form. Milk production and composition were not influenced by the processing method and there was no significant difference between the treatments in terms of ruminal VFA and $\mathrm{pH}$. The highest dry matter digestibility was observed when both barley and corn were steam-flaked and used in un-pelleted concentrate which was $5.12 \%$ greater when both grains were ground. However, the potential benefits of steam-flaking over pelleting could not be explored by this study, unless there had been pelleted as a fifth treatment.

A more comprehensive study in this regard was conducted by Hutjens (1999). He documented an experiment on lactating dairy cow fed with $460 \mathrm{~g} / \mathrm{kg}$ forage and one of the five following concentrate mixtures which were similar in formula: 1) ground corn in the complete concentrate pellet, 2) ground corn and pellet of other ingredients, 3) cracked corn plus pellet of other ingredients, 4) steam-flaked corn together with pellet of other ingredients, and 5) blend of fine ground (0.45) and steam-flaked (0.55) corn plus pellet of other components. Dry matter intakes were 26.60, 25.34, $24.75,23.99$ and $23.58 \mathrm{~kg}$ per day for the treatments 1 to 5, respectively. Milk yields however, were $43.38,42.71,40.73,44.19$ and $43.25 \mathrm{~kg}$ per day for the above treatments, respectively which indicated an equality for ground corn in the complete concentrate pellet and steam-flaked corn together with pellet of other concentrate ingredients.

Aggregation of small particles by moisture, steam and mechanical pressing produces pellet particles which minimize the chance of sorting by animals and lead to the consumption of a balanced diet per bite. When concentrate consists of a blend of steam-flaked grains and some un-pelleted components, it is possible to influence the pattern and amount of intake. For instance, Brown et al. (1970) used pelleted and un-pelleted milo-barley concentrate mixtures in addition to alfalfa hay $(0.55)$ for feeding lactating dairy cows. Both grains were ground for pelleted concentrate; however, in the un-pelleted mixture, grains were steam-flaked and mixed with other ingredients. The formulation of the concentrates was as follows: milo, barley, cotton seed meal, molasses and salt at the ratio of $178,554,198,60$ and $10 \mathrm{~g} / \mathrm{kg}$, respectively. The results indicated no significant difference between the treatments in terms of their effect on milk production and composition. Dry matter intake was reduced as a consequence of feeding steam-flaked grains and mash of the other parts. This 
reduction was attributed to finely ground cottonseed meal and pelleting increased dry matter intake when the trail was repeated. As it appears from the above findings, the combination of grains steam-flaking and pelleting of the rest of the ingredients in the concentrate mixture resulted in better overall performance.

\section{Conclusion}

Overall, pelleting technology should be still used alongside steam-flaking method for obtaining numerous pellet advantages such as reducing transportation cost, dust, sorting, bird removal etc. for all species of ruminants. Considering possibility of about two-fold reduction in mean particle size during pelleting, optimized mean particle size for corn $(0.7-1 \mathrm{~mm})$ and barley $(0.93-2.4 \mathrm{~mm})$ grains, it can be suggested that pre-pelleting grinding of corn and barley grains for the aim of using in the pelleted concentrate with lower acidosis risk should not result in ground materials with lesser than $1.8 \mathrm{~mm}$ mean particle size. Regarding upper limit of grains mean particle size which certainly depends on the species of animal, further comparative study is required with monitoring starch measurements in feces. Equality of starch utilization from steam-flaked grains in concentrate with complete concentrate pellets having grains prepared with above recommendations deserves further research. Care must be taken to use different hammer mills for barley and corn grains, otherwise adjusted operating conditions for desirable corn mean particle size may result in finer ground barley which at the end might be detrimental for rumen health in ruminants consuming high levels of pelleted concentrate. Under the situation where consuming steam-flaked grains has priority of usage in the diet, it is strongly recommended to pellet non-grain portions of concentrate. Because steam-flaking of grains increases bulk, further cost-benefit researches are also required to assess the benefits of steam flaking over complete concentrate pellet considering processing and transportation costs, animal factors and rumen health.

\section{Conflict of interest}

The authors declare no conflict of interest.

\section{Acknowledgments}

This research did not receive any specific grant from funding agencies in the public, commercial, or not-for-profit sectors. Ferdowsi University of Mashhad, Mashhad, Iran provided opportunity to author for preparing this review.

\section{References}

Abdollahi M.R., Ravindran V., Wester T.J., Ravindran G., Thomas D.V. (2010). Influence of conditioning temperature on performance, apparent metabolisable energy, ileal digestibility of starch and nitrogen and the quality of pellets, in broiler starters fed maize- and sorghum-based diets. Anim. Feed Sci. Technol., 162: 106-115.

A b d o 11 ah i M.R., R a vind ra n V., S v i hu s B. (2013). Pelleting of broiler diets: An overview with emphasis on pellet quality and nutritional value. Anim. Feed Sci. Technol., 179: 1-23. 
A 1 - R a b a d i G.J.S. (2013). The effect of hammer mill screen size on processing parameters and starch enrichment in milled barley. Jordan J. Agric. Sci., 9: 162-169.

A l-R abadi G.J.S., Gilbert R.G., Gidley M.J. (2009). Effect of particle size on kinetics of starch digestion in milled barley and sorghum grains by porcine alpha-amylase. J. Cereal Sci., 50: 198-204.

A l-R abadi G.J., Torley P.J., Will i a m s B.A., B ryden W.L., Gidley M.J. (2011). Effect of extrusion temperature and pre-extrusion particle size on starch digestion kinetics in barley and sorghum grain extrudates. Anim. Feed Sci. Technol., 168: 267-279.

Anguita M., Gas a J., Martín-Orú e S.M., Pérez J.F. (2006). Study of the effect of technological processes on starch hydrolysis, non-starch polysaccharides solubilization and physicochemical properties of different ingredients using a two-step in vitro system. Anim. Feed Sci. Technol., 129: 99-115.

Armbruster S. (2006). Steam flaking grains for feedlot cattle: A consultant's perspective. Proc. Cattle Grain Processing Symposium. Oklahoma State University, Tulsa, Oklahoma, pp. 46-61.

A t t a r A., Kermanshahi H., Golian A. (2018). Effects of conditioning time and sodium bentonite on pellet quality, growth performance, intestinal morphology and nutrient retention in finisher broilers. Brit. Poultry. Sci., 59: 190-197.

B edford M.R., P artridge G.G. (2010). Thermostability of feed enzymes and their practical application in the feed mill. In: Enzymes in farm animal nutrition, Bedford M.R., Partridge G.G. (eds). CABI, Oxfordshire, UK, p. 368.

B e r t i pa g li a L.M.A., F on d e vila M., van La a r H., Castrillo C. (2010). Effect of pelleting and pellet size of a concentrate for intensively reared beef cattle on in vitro fermentation by two different approaches. Anim. Feed Sci. Technol., 159: 88-95.

B l a s e 1 H.M., H o ffm a n P.C., S h a v e r R.D. (2006). Degree of starch access: An enzymatic method to determine starch degradation potential of corn grain and corn silage. Anim. Feed Sci. Technol., 128: $96-107$.

B rown W.H., Sullivan L.M., Che a tham L.F., Halbach K.J., Stull J.W. (1970). Steam processing versus pelleting of two ratios of milo and barley for lactating cows. J. Dairy Sci., 53: $1448-1454$.

B r u in s m a J. (2003). World agriculture: towards 2015/2030. An FAO perspective. London.

Ca 11 i s on S.L., F ir k in s J.L., E a s tridge M.L., H u 11 B.L. (2001). Site of nutrient digestion by dairy cows fed corn of different particle sizes or steam-rolled. J. Dairy Sci., 84: 1458-1467.

Carlson J.C., Stahl R.S., De Liberto S.T., Wagner J.J., Engle T.E., Engeman R.M., Ols o n C.S., E 11 is J.W., Werner S.J. (2018). Nutritional depletion of total mixed rations by European starlings: Projected effects on dairy cow performance and potential intervention strategies to mitigate damage. J. Dairy Sci., 101: 1777-1784.

Castrillo C., Mota M., Van Laar H., Martín-Tereso J., Gimeno A., Fondevila M., $\mathrm{G} \mathrm{u}$ a d a J.A. (2013). Effect of compound feed pelleting and die diameter on rumen fermentation in beef cattle fed high concentrate diets. Anim. Feed Sci. Technol., 180: 34-43.

Coon R.E., Duffield T.F., De Vries T.J. (2018). Effect of straw particle size on the behavior, health, and production of early-lactation dairy cows. J. Dairy Sci., 101: 6375-6387.

Corona L., Rodriguez S., Ware R.A., Zinn R.A. (2005). Comparative effects of whole, ground, dry-rolled, and steam-flaked corn on digestion and growth performance in feedlot cattle. Prof. Anim. Sci., 21: 200-206.

Fahrenholz A.C. (2012). Evaluating factors affecting pellet durability and energy consumption in a pilot feed mill and comparing methods for evaluating pellet durability. PhD Diss. Kansas State University.

F e rrare t to L.F., Cru m p P.M., Sh a ver R.D. (2013). Effect of cereal grain type and corn grain harvesting and processing methods on intake, digestion, and milk production by dairy cows through a meta-analysis. J. Dairy Sci., 96: 533-550.

G a 11 o A., Gi ub ert i G., M a s o e r o F. (2016). Gas production and starch degradability of corn and barley meals differing in mean particle size. J. Dairy Sci., 99: 4347-4359.

G a 11 o A., G i u b e r t i G., A t z o r i A.S., M a s o e r o F. (2018). Short communication: In vitro rumen gas production and starch degradation of starch-based feeds depend on mean particle size. J. Dairy Sci., 101: 6142-6149. 
G a ly e a n M.L., Wa g n e r D.G., O w e n s F.N. (1981). Dry matter and starch disappearance of corn and sorghum as influenced by particle size and processing. J. Dairy Sci., 64: 1804-1812.

Ghorbani G.R., Moradi-Ghahderijani A., Alikhani M. (2002). Effects of barley grain particle size on dairy cow performance (abstract in English). Iran Agric. Res., 21: 119-132.

Gimeno A., Alami A. Al, Toral P.G., Frutos P., Abecia L., Fondevila M., Castril lo C. (2015). Effect of grinding or pelleting high grain maize- or barley-based concentrates on rumen environment and microbiota of beef cattle. Anim. Feed Sci. Technol., 203: 67-78.

Gutierrez B.H., Alvarez E.G., Montano M.F., Salinas-Chavira J., Torrentera N.G., Zinn R.A. (2018). Influence of flake density and tempering on the feeding value of steam-flaked corn for feedlot cattle. J. Appl. Anim. Res., 46: 155-158.

H u t j e n s M. (1999). Ration physical form and rumen health. Proc. 4-State Dairy Nutrition \& Management Conference, pp. 1-3.

Karimizad e h E., Chaj i M., Moh a m mad a ba d i T. (2017). Effects of physical form of diet on nutrient digestibility, rumen fermentation, rumination, growth performance and protozoa population of finishing lambs. Anim. Nutr., 3: 139-144.

K a z e m i - B o n c he n ar i M., S a l e m A.Z.M., Ló p e z S. (2017). Influence of barley grain particle size and treatment with citric acid on digestibility, ruminal fermentation and microbial protein synthesis in Holstein calves. Animal, 11: 1295-1302.

$\mathrm{K}$ h a n G. (2014). Effects of hammer milling, roller milling and pelleting on technical and nutritive value of barley for ruminants. MSc Diss. Norwegian University of Life Sciences.

K n ow 1 t o n K.F., A 11 e n M.S., E r i c k s o n P.S. (1996). Lasalocid and particle size of corn grain for dairy cows in early lactation. 1. Effect on performance, serum metabolites, and nutrient digestibility. J. Dairy Sci., 79: 557-564.

K o e n i g K., B e a u c h e m in K. (2011). Optimum extent of barley grain processing and barley silage proportion in feedlot cattle diets: Growth, feed efficiency, and fecal characteristics. Can. J. Anim. Sci., 91: 411-422.

L e w is L.L. (2014). Evaluation of pelleting process parameters on feed nutrients, starch gelatinization and pig growth performance. MSc Diss. Kansas State University.

L y k o s T., Va rg a G.A. (1995). Effects of processing method on degradation characteristics of protein and carbohydrate sources in situ. J. Dairy Sci., 78: 1789-1801.

Mats u s him a J.K. (1979). Feeding beef cattle, Advanced series in agricultural sciences. SpringerVerlag, New York.

Mats u s him a J.K. (2006). History of feed processing. Proc: Cattle Grain Processing Symposium. Colorado State University, Tulsa, Oklahoma, pp. 1-16.

Moya D., He M.L., Jin L., Wang Y., Penner G.B., Schwartzkopf-Genswein K.S., M c A 11 is ter T.A. (2015). Effect of grain type and processing index on growth performance, carcass quality, feeding behavior, and stress response of feedlot steers. J. Anim. Sci., 93: 3091-3100.

Muramatsu K., Maiorka A., Dahlke F., Lopes A., P a s che M. (2014). Impact of particle size, thermal processing, fat inclusion, and moisture addition on starch gelatinization of broiler feeds. Rev. Bras. Ciência Avícola, 16: 367-374.

N e t e m e y e r D.T., B u s h L.J., O w e n s F.N. (1980). Effect of particle size of soybean meal on protein utilization in steers and lactating cows. J. Dairy Sci., 63: 574-578.

NRC (2001). Nutrient Requirement of Dairy Cattle, 6th rev. ed. National Academy of Sciences, Washington, DC.

Oliveira J.S., Huber J.T., Ben-Ghedalia D., Swingle R.S., Theurer C.B., P ess a r a k li M. (1993). Influence of sorghum grain processing on performance of lactating dairy cows. J. Dairy Sci., 76: 575-581.

P la s c e n c i a A., Z in n R.A. (1996). Influence of flake density on the feeding value of steam-processed corn in diets for lactating cows. J. Anim. Sci., 74: 310-316.

P las cencia A., González-Vizcarra V.M., Zinn R. (2018). Comparative effects of grain source on digestion characteristics of finishing diets for feedlot cattle: steam-flaked corn, barley, wheat and oats. Can. J. Anim. Sci., 98: 794-800.

Q i a o F., Wang F., R en L., Z h o u Z., M en g Q., B a o Y. (2015). Effect of steam-flaking on chemical compositions, starch gelatinization, in vitro fermentability, and energetic values of maize, wheat and rice. J. Integr. Agric., 14: 949-955. 
Raaijmakers M.M.P., van Loon J., Elling-Stats M.L., van der Poel A.F.B., K w a k k e l R.P. (2017). Effect of whole wheat inclusion and pellet diameter on pellet quality and performance in broilers. Proc. 21st European Symposium on Poultry Nutrition. Salou/Vila - Seca, Spain, pp. 1-4.

R e e c e F.N., L o tt B.D., D e a t o n J.W. (1986). The effects of hammer mill screen size on ground corn particle size, pellet durability, and broiler performance. Poultry Sci., 65: 1257-1261.

Rémond D., Cabrera-Estrad a J.I., Champion M., Chauveau B., Coudure R., P on c e t C. (2004). Effect of corn particle size on site and extent of starch digestion in lactating dairy cows. J. Dairy Sci., 87: 1389-1399.

Rus s o V.M., Le ury B.J., Kenned y E., Hannah M.C., A u ld is t M.J., Wal e s W.J. (2018). Forage type influences milk yield and ruminal responses to wheat adaptation in late-lactation dairy cows. J. Dairy Sci., 101: 9901-9914.

Safaei K., Ghorbani G.R., Alikhani M., Sadeghism A., Yang W., Saebi-Far M. (2017). Effects of grinding versus steam-flaking on feeding value of blending barley and corn in low-forage diets fed to dairy cows. J. Anim. Sci., 95: 292.

S chwandt E.F., Hubbert M.E., Thom s on D.U., Vahl C.I., B a rt le S.J., R e in hard t C.D. (2016). A survey of starch availability of steam-flaked corn in commercial feedlots evaluating roll size and flake density. Prof. Anim. Sci., 32: 550-560.

S chwandt E.F., Thom s o n D.U., B a rt le S.J., R e inh ard t C.D. (2017). A survey of dry processed corn particle size and fecal starch in midwestern U.S. feedlots. Kansas Agric. Exp. Stn. Res. Reports, 3: 1-4.

Shin-ichi T., Norio Y., Yukihiro I., Ken-i chi H., Toshiyoshi T., Maria W., Kei T., Syuhei I., Toy oji M. (2016). The effect of pelleting on in situ rumen degradability of compound feed containing brown rice for dairy cows. Anim. Sci. J., 88: 185-189.

S t a rk C.R. (1994). Pellet quality and its effect on swine performance; functional characteristics of ingredients in the formation of quality pellets. PhD Diss. Kansas State University, Manhattan.

S t e ve n s C.A. (1987). Starch gelatinization and the influence of particle size, steam pressure and die speed on the pelleting process. PhD Diss. Kansas State University, Manhattan.

Yang W.Z., B e a u c h e m in K.A., R o d e L.M. (2000). Effects of barley grain processing on extent of digestion and milk production of lactating cows. J. Dairy Sci., 83: 554-568.

Z i n n R.A. (1990). Influence of steaming time on site of digestion of flaked corn in steers. J. Anim. Sci., 68: 776-781.

Z in n R.A., O w e n s F.N., W a r e R.A. (2002). Flaking corn: processing mechanics, quality standards, and impacts on energy availability and performance of feedlot cattle. J. Anim. Sci., 80: 1145-1156.

Received: 27 II 2019

Accepted: 6 VIII 2019 